\title{
Advancing towards contemporary practice: a systematic review of organisational performance measures for non-acute health charities
}

\author{
Richard Colbran ${ }^{1 *}$ (D), Robyn Ramsden ${ }^{2}$, Karen Stagnitti ${ }^{2}$ and John W. Toumbourou ${ }^{3}$
}

\begin{abstract}
Background: Organisational performance measurement is a recognised business management tool and essential for survival and success. There is a paucity of methodological studies of organisational performance measurement relating to non-acute healthcare charities and this study is the first to suggest a set of evidence-informed organisational performance measures for the sector.

Methods: This study was designed using a two-staged approach. A systematic review of peer-reviewed journal literature between 2003 and 2016 was conducted according to the twenty-seven (27) point checklist of the Preferred Reporting Items for Systematic Reviews and Meta-Analyses (PRISMA) complemented by a thematic analysis of eligible data using a cutting and sorting technique to generate a set of common measures of organisational performance for non-acute health charities.

Results: Not one study was found relating to organisational performance of non-acute healthcare charities however four records met eligibility criteria relating to non-acute or primary healthcare services with charitable fundraising capability. Three were case studies of specific organisations that related their approach to organisational performance measurement, while the fourth compared a case study organisation to a public service. Three different organisational performance frameworks and 20 organisational performance measures were used across the four studies.

Conclusions: The study concluded that (1) demonstration of organisational performance is relevant to non-acute health charities; (2) organisational performance measurement is feasible in this sector; (3) an evidence-based organisational performance measurement framework for the sector has not yet been developed nor has an existing organisational performance measurement framework been adapted for the sector, although the Balanced Scorecard is likely to be an effective option and (4) five leading measures - Quality of Service; Finance; Stakeholders (Customers and Clients); People and Culture; and Governance and Business Management; could be used to determine organisational performance in these sectors. Finally, 'Mission and Purpose' could be explored as a potential measure. Further research to understand why there is such limited published organisational performance evidence for the sector could be useful. Case studies of organisational measurement strategies of successful non-acute healthcare charities and research into important factors for organisational performance implementation in the sector may contribute to greater uptake and knowledge dissemination.
\end{abstract}

Keywords: Organisational performance measurement, Non-acute healthcare, Non-government, Non-profit, Charity

\footnotetext{
* Correspondence: rcolbran@nswrdn.com.au

${ }^{1}$ New South Wales (NSW) Rural Doctors Network, Hamilton, NSW, Australia

Full list of author information is available at the end of the article
}

(c) The Author(s). 2019 Open Access This article is distributed under the terms of the Creative Commons Attribution 4.0 International License (http://creativecommons.org/licenses/by/4.0/), which permits unrestricted use, distribution, and reproduction in any medium, provided you give appropriate credit to the original author(s) and the source, provide a link to the Creative Commons license, and indicate if changes were made. The Creative Commons Public Domain Dedication waiver (http://creativecommons.org/publicdomain/zero/1.0/) applies to the data made available in this article, unless otherwise stated. 


\section{Background}

Internationally, the nonprofit sector continues to grow in importance and visibility [1]. In health, the evolving role of non-government health services and charities is recognised by the World Health Organisation's Civil Society Initiative [2]. Non-acute health charities form part of this broader global industry and play a significant role in providing a range of non-hospital and maintenance-care services across many health and wellbeing disciplines often in a complementary manner with other non-charity social services such as education, disability, mental health, aged care, rehabilitation, justice and welfare. Despite the broad scope of non-acute health charities, the sector is treated somewhat homogenously in the health care system as such organisations are governed independently; have a broad range of stakeholder groups [4]; have common funding options through government contracts, donations, fee-for-service and membership; are intrinsically connected by their charitable reason-for-being [3, 4]; do not have a profit motive [5]; and benefit from unique governance legislation that allows them to function with not-for-profit status eligible for donations or tax concessions.

While non-government organisations, not-for-profits and charities share service workloads with government and for-profit providers [3] an outcome of global growth has been increased competition ([4], p. 353); an escalation of concern regarding organisational effectiveness, excellence and accountability [5]; and stakeholder agreement that charities should be well governed ([3], p. 48) and held accountable ([3], p. 50). Organisational performance measurement is "essential to the survival and success of the modern business" ([6], p. 719) and is distinct from program effectiveness in that it is not the same as summed program level measures ([7], p. 477) and provides operational and benchmarking data that can guide improvement over time, rather than point in time program level measures. Demonstrating organisational performance is likely to be advantageous in the not-for-profit and charitable health care sector as there is a link between organisational performance measurement and organisational excellence ([8], p. 182) and it can demonstrate "efficiency and effectiveness in providing services" to clients [9].

The healthcare industry itself has a long tradition of extensive and detailed performance measurement [10], however it appears the focus has predominately been on hospital, acute or clinical settings and jurisdictional systems as described by Zelman, Pink and Matthias [11] and not on the nonprofit and charity health industry. The relationship between performance measurement and organisational effectiveness in nonprofit organisations is addressed in published literature [12] however the uptake of organisational performance measurement within not-for-profit sectors has been slow ([7], p. 478). There is an empirical research literature gap for organisational performance of third sector or not-for-profit primary health care service provision ([13], p. 599 and [14]) and the sector faces a "dangerous blind spot" ([15], p.35) emanating from a dearth of robust performance data for the sector which has resulted in it being poorly understood, under-supported and potentially under-valued. There is still little consensus as to "what are the best measures of performance" ([16], p. 59) nor is there an accepted standard of measuring effectiveness. The lack of published literature does not signal that organisational performance measurement is not being implemented in non-acute health charities. It may indicate that efforts have not been methodologically designed or factors for successful implementation have been retained by organisations or not reported. The organisational performance measurement process is difficult with upwards of $70 \%$ implementation failure rate [17] which reinforces the need to identify features of successful implementations $([17,18]$, p. 7$)$ so that a central repository of learning and knowledge can be used by the sector's leaders to inform their approach for change within their organisations.

Characteristics of non-acute health charity business models may be a challenge to organisational performance measurement. The difficulties associated with the conceptualisation of organisational performance due to the financial and legal status and goals of charities, which are based on social values, were documented back in the 1980s and 1990s ([16], p. 59). More recently it is suggested that the absence of a single end product ([7], p. 477) and the presence of multiple stakeholder groups ([7], p. 477 and [19], p. 34) create further complications. These coupled with the need to balance clinical and corporate governance responsibilities, and non-profit cultures that do not encourage accountability ([20], p.16) and restrict the introduction of contemporary professional standards ([19], p. 34) are also cited.

In terms of organisational performance measurement methodology, the World Health Organisation's 2008 European Ministerial Conference Report [21] on the use of performance measurement for health system improvement identified conceptual frameworks as a key element of stewardship responsibilities for leaders when pursuing performance measurement for health system improvement. There are a number of organisational performance measurement frameworks or tools available for practitioners identified in literature across for-profit, public and not-for-profit industry such as Balanced Scorecard, Multi-criteria analysis [22], UTASTAR [22], Public Sector Scorecard [22], Total Quality Management [23], Peer-review analysis [24] and Social Return on Investment (SROI). 
The decision regarding the choice of organisational measures is reportedly one of the major considerations for framework design as the metrics chosen should relate directly to the "organisation's planned processes and targeted outcomes" ([25], p. 11). Any theoretical framework for performance measurement requires reference points such as measures to assess success or performance to be developed ([21], p. 6). These reference points or measures are fundamental and the lack of published literature across any of the performance tools specifically relating to the measures of organisational performance of non-acute charities suggests measures for the sector have not yet been created, adapted or tested. The difficulty in determining appropriate measures that integrate accountability with sustainability ([3], p. 51), and the time consuming need for flexibility to suit individual organisations ([26], p.79), are likely to be a challenging barriers to the introduction of an organisational performance measurement model in the sector. Authors including Gurd and Gao [17], Gomes and Liddle [27], Zimmerman [25], Bisbe and Barrubes [28], and Boateng et al. [16] suggest variations to organisational performance measures for healthcare organisations or charities.

In accepting the challenges of undertaking organisational performance measurement in the non-profit charity health sector, a clear benefit for investment and risk must also be established for both pursuing sector-specific understanding and also individual organisation implementation. The reality is that for organisational performance measurement to be successful "it is essential to take into account the specificities of the sector" ([28], p. 926) and must also be tailored to suit individual organisations. Organisational performance measurement seeks to "monitor, evaluate and communicate" the extent to which an organisation meets its objectives ([21], p. 2). So while organisational performance frameworks or tools may be transferable across for-profit, public and not-for-profit industry; or for that matter, individual sector types such as acute, non-acute, primary or community health care; success factors across industry or sector types should not be assumed as being similar as no two organisations will have the identical objectives. Hence the need for creating measures to allow comparison of tailored performance indicators developed for individual organisations within a sector such as non-acute health charities.

The survival of non-acute health charities may be threatened if they do not accept the new age of corporate and service responsibilities, contemporary business management and stakeholder expectations for accountability and excellence. The identification of evidence-informed organisational performance frameworks and measures for non-acute health charities may in-part help overcome the barriers for measurement implementation in the sector, and in turn encourage demonstration of effective business strategy and client care outcomes. Creating a competitive edge through reporting organisational performance in service, stakeholder engagement, and funding could just be what the doctor ordered for non-acute health charities to sustain their programs ([20], p. 32) and enhance their prospects of long-term success and sustainability.

This study sought to answer the question: What are the important organisational performance measures of non-acute health charities? The specific aims were to (1) gauge the extent of quality methodological studies of organisational performance measurement frameworks for non-acute healthcare charities; (2) source studies from the sector which have evaluated the feasibility, validity and effectiveness of frameworks in improving organisational performance and client care outcomes; and (3) determine which measures were most valuable to assess the performance of such organisations.

\section{Methods}

This study was designed using a two-staged approach. Firstly, a systematic review - widely accepted as a gold standard in evidence synthesis [29], was conducted according to the twenty-seven (27) point checklist of the Preferred Reporting Items for Systematic Reviews and Meta-Analyses (PRISMA) flow statement described by Moher, Liberati, Tetzlaff and Altman [30]. This review sought to source studies that identify measures that assess the performance of non-acute health charities, and studies that evaluated the feasibility, validity and effectiveness of frameworks in improving organisational performance and client care outcomes in such organisations. The PRISMA systematic review method was chosen as it is highly regarded systematic review method as evidenced by the fact it is the preferred reporting guideline of the international EQUATOR (Enhancing the QUAlity and Transparency Of health Research) Network that seeks to improve the reliability and value of published health research literature [31] and would assure the research study's integrity and enhance transparency.

This first stage was then complemented by a thematic analysis of eligible data using a cutting and sorting technique informed by Ryan and Bernard ([32], p. 94) to generate a set of common measures of organisational performance of non-acute health charities.

\section{Stage 1: PRISMA compliant systematic review Eligibility criteria}

The study sought scholarly peer-reviewed literature, published between 2003 and 2016, available in English and full-text online relating to organisational performance measurement of non-government organisations 
(NGOs) in the not-for-profit (NFP) or charitable sectors that provide non-acute healthcare.

Internationally there is a wide perspective of definitions relating to non-government, not-for-profit and charitable sectors depending on the field of topic studied ([5], p. 437; [12], p. 697). For the purposes of this study, the organisation variables were defined as -

Non-government organisations (NGOs): organisations that are not government or public institutions. When excluding for-profit businesses, such organisations are often referred to as the 'third-sector' and characterised by a vision to contribute to community issues.

Not-for-Profit organisations (NFPs): NGOs where all of the revenue earned is utilised to pursue the organisation's objectives. Profits are not distributed back to owners, shareholders or members.

Charitable organisations: NFPs that are legally eligible for donations or specific tax concessions.

Non-acute healthcare: the provision of non-hospital health service where the primary clinical purpose is support for a patient with impairment or activity limitation due to a health condition. Often referred to as maintenance care, non-acute patients often require care over an indefinite period following initial assessment or treatment as opposed to complex stabilisation.

\section{Search information sources}

Table 1 identifies the electronic databases accessed through EBSCOHost and the five primary search fields. Each search utilised variations of Boolean operators (AND, OR, * and Parentheses) and was complemented by GoogleScholar. Additional records were sourced through peer checking and inspecting reference lists. This search activity was conducted between January 2015 and June 2015, and updated in December 2016.

\section{Study selection}

Table 2 outlines the Study's PRISMA flowchart indicating search strategy and process.

The goal was to assess studies of organisations that met all three organisational characteristics - NGO, NFP and charitable eligibility, which provided non-acute healthcare services.

Inclusion criteria were used in the second (screening) and third (eligibility) stages of the four staged PRISMA-flow process. The inclusion decisions were made by the lead author and critiqued by the second

Table 1 PRISMA Stage 1 Search Strategy and Electronic Databases

PRISMA Stage 1: Identification of records Database search strategy

Five (5) search fields featuring variations of the key study words were targeted using EBSCOHost as the primary search platform supported by GoogleScholar. Each search utilised variations of Boolean operators (AND, OR, ${ }^{*}$ for multiple character wildcard searches, and Parentheses to specify the order of search interpreptation).

1: Organisation performance of NGOs, third-sector, non-government organisations, non-profit organisations

2: Organisation performance of health services - non-acute, primary health

3: Organisation performance of health services - child and paediatric

4: Organisation performance of health services - non-profit, NPO, third-sector, non-government

5: Health organisations, paediatric health, child health, primary health, non-acute health, non-profit organisations, non-government organisations, NGOs, non-government health, non-government primary health, third sector, third sector health, third sector child health

Databases utilised in search

A+ Education, Academic OneFile, AINHAL Complete, Applied Science \& Technology

Source, Art Source, Arts \& Humanities Citation Index, Business Source Complete, CINAHL

Complete, Communication \& Mass media Complete, Criminal Justice Abstracts with

Full Text, Directory of Open Access Journals, Education Source, Environment Complete,

ERIC, Expanded Academic ASAP, Garden, Landscape \& Horticulture Index, General

OneFile, General Reference Center Gold, GrnFILE, Health Policy Reference Center,

Humanities Source, Historical Abstracts with Full Text, Info Trac Health Reference

Center Academic, International Biliography of Theatre \& Dance with Full Text,

Jewish Studies Source, JSTOR Journals, JSTOR Arts \& Sciences, JSTOR Arts \&

Sciences IV, JSTOR Arts \& Sciences VI, JSTOR Arts \& Sciences IX, Legal Source,

Library \& Information Science Source, Library \& Information Science \&

Technology Abstracts, MAS Ultra - School Edition, MasterFILE Premier,

MEDLINE Complete, MLA International Bibliography, Philosopher's Index,

Political Science Complete, PsychINFO, Science Citation Index, ScienceDirect,

Social Sciences Citation Index, SociNDEX with Full Text, Social Works

Abstracts, SPORTDiscus with Full Text, Urban Studies Abstracts 
Table 2 PRISMA Flow Chart

\begin{tabular}{|c|c|c|}
\hline Stage 1: Identification & $\begin{array}{l}\text { Published articles identified through } \\
\text { database search } \\
\text { - Phase 1: Database search strategy }(n=17,823) \\
\text { - Phase 2: Additional records identified through } \\
\text { peer feedback and reference checks }(n=217)\end{array}$ & $\begin{array}{l}\text { Records identified through five database search strategy fields - } \\
\text { 1: Organisation performance of NGOs, third-sector, non-government } \\
\text { organisations, non-profit organisations } \\
\text { 2: Organisation performance of health services - non-acute, primary } \\
\text { health } \\
\text { 3: Organisation performance of health services - child and paediatric } \\
\text { 4: Organisation performance of health services - non-profit, NPO, } \\
\text { third-sector, non-government } \\
\text { 5: Health organisations, paediatric health, child health, primary } \\
\text { health, non-acute health, non-profit organisations, non-government } \\
\text { organisations, NGOs, non-government health, } \\
\text { non-government primary health, third sector, third sector health, } \\
\text { third sector child health }\end{array}$ \\
\hline Stage 2: Screening & $\begin{array}{l}\text { Records screened } \\
(n=18,040)\end{array}$ & $\begin{array}{l}\text { Records excluded }(\mathrm{n}=17,780) \text { for not meeting inclusion criteria - } \\
\text { - Published between } 2003 \text { and } 2015 \text { (excluded =3354, } \\
\text { included = 14,686) } \\
\text { - Scholarly peer-reviewed literature (excluded }=7409 \text {, } \\
\text { included }=7277 \text { ) } \\
\text { - Available in English and full-text online (excluded = 39, } \\
\text { included }=7238 \text { ) } \\
\text { - Abstract confirmed record related to organisational performance } \\
\text { measurement and healthcare (excluded }=6973 \text {, included }=265 \text { ) } \\
\text { - Removal of duplications (excluded }=5 \text {, included }=260 \text { ) }\end{array}$ \\
\hline Stage 3: Eligibility & $\begin{array}{l}\text { Full text articles assessed for eligibility } \\
(n=260)\end{array}$ & $\begin{array}{l}\text { Records excluded }(n=256) \text { for not meeting eligibility criteria - } \\
\text { - Study relates to an organisation providing Health and Social } \\
\text { Services (excluded }=1 \text {, eligible }=255 \text { ) } \\
\text { - Study relates to Organisational Performance Measurement } \\
\text { Framework including Measures (excluded }=195 \text {, eligible }=60 \text { ) } \\
\text { - Study relates to, or makes reference to, delivery of non-acute } \\
\text { health services }=(\text { excluded }=46 \text {, eligible }=14 \text { ) } \\
\text { - Provides a complete Organisational Performance Measurement } \\
\text { Framework including Measures (excluded }=6 \text {, eligible }=8 \text { ) } \\
\text { - Study relates to organisational performance in non-government } \\
\text { organisation/s (excluded }=8 \text {, eligible }=4 \text { ) } \\
\text { - Study relates to organisational performance in non-for-profit } \\
\text { or charitable organisation } / \mathrm{s} \text { (excluded }=0 \text {, eligible }=4 \text { ) }\end{array}$ \\
\hline Stage 4: Included & $\begin{array}{l}\text { Studies included in qualitative } \\
\text { synthesis } \\
(n=4)\end{array}$ & \\
\hline
\end{tabular}

Flow of information through the phases of the PRISMA compliant systematic review a systematic review including the number of records identified, included and excluded at each phase

and third authors. Records were sought that were scholarly peer-reviewed literature, published between 2003 and 2016 available online in English and in full-text. Two-hundred and sixty (260) articles published between 2003 and 2016 were identified as relevant. Full-text assessment of these publications (Stage 3) was then undertaken using six eligibility criteria.

The authors agreed that there were no articles sourced that related solely to organisational performance of non-acute healthcare charities, however four articles met the inclusion criteria (see Table 2). Internet searches were conducted on the case study organisations identified within the eligible records to confirm their corporation status, governance structures and service types.

Before proceeding, the potential impact of sourcing only four eligible records on the study's validity was considered. A review of literature relating to low or nil record systematic reviews - otherwise known as 'empty reviews', suggested they occur for a variety of reasons; however they are not uncommon and many are listed within the Cochrane Database of Systematic Reviews [33]. Empty reviews are still important although are at risk of misguided conclusions if not well constructed ([34], p. 596). Although no eligible records were sourced relating to organisational performance of non-acute health charities, as the review was PRISMA compliant, the authors chose to proceed with analysis of the four records that met the inclusion criteria as they provided the closest information to the target sector.

\section{Stage 2: Data collection process and theming}

The eligible studies were reviewed and the following data were extracted: 1) authors names 2) publication 3) year of publication 4) country of origin 5) key search terms 6) article key words 7) organisational performance measurement framework studied and 8) organisational performance measures utilised for the framework. A quality assessment of the eligible studies was also 
conducted using the four categories of The Rosalind Franklin Qualitative Research Appraisal Instrument RF-QRA ([35], p.37) - credibility, transferability, dependability and confirmability. The risk of bias was determined to be low. Each record was defined as published peer-review literature and was assessed as being trustworthy using RF-QRA by the research team.

The performance measures for each study were collated using a cutting and sorting technique ([32], p. 94) whereby quotes or expressions that related to the study aim were identified as themes. The results were tabulated into a list of repeating or similar themes from which a table of common measures were generated.

\section{Results}

\section{Study selection}

Table 3 identifies the four records that met the eligibility criteria and had data extracted. An RF-QRA analysis for each record is also included.

A 2008 Canadian study by Schalm [36] details the development of a corporate Balanced Scorecard (BSC) program for The Capital Care Group - a continuing care organisation. The study details strategies for balanced scorecard implementation and offers the BSC factors and indicators used by the case study organisation along with seven lessons learnt ([36], p. 13).

A 2007 study by Mueller [3] introduced the role of NFP healthcare providers and paid particular attention to their need for financial responsibility and sustainable relationships with funders. The difficulty of non-profit performance measurement is highlighted given "the diverse environment and diffuse outcome objectives of many NPOs" ([3], p.47). The study reported on a field trial of the Looking Glass Evaluation Tool with a Primary Health Organization (PHO) in New Zealand, to determine the effectiveness of its organizational activities.

Published in 2006, Laamanen et al. [13] compared primary healthcare provided by an independent not-for-profit organization (INPO) with that provided by two Finnish public municipal organisations in terms of clients' perceptions of performance, acceptance, and trust. The study derived from the changes connected with "new public management" ([13], p. 598) involving consumer choice and production of services based on market procedures. The study offers a scale of consumer assessment and found clients of the INPO generally rated the service more positively than clients of publicly provided services.

The BSC is the focus of Radnor and Lovell's 2003 study [37], which offered a needs analysis for organisation performance systems and an in-depth account of the BSC and its history within the UK's National Health System. The steps of BSC development within a local
Primary Care Trust (PCT) is described, along with the indicators used and a summary of lessons learnt.

\section{Study characteristics}

Three of the studies were case studies of specific organisations (Mueller [3], Schalm [36], and Radnor and Lovell [37]) and their approach to organisational performance measurement, while the fourth compared a case study organisation to a public service (Laamanen et al. [13]). The four records originated in different countries Canada (Schalm [36]), New Zealand (Mueller [3]), Finland (Laamanen et al. [13]) and United Kingdom (Radnor and Lovell [37]), and were published in a variety of journals between 2003 and 2008. There was a broad range of electronic database search terms and key words, with little commonality identified between each article, suggesting the terminology in the field is underdeveloped.

Each of the case study organisations delivered non-acute care, however none identified it as their sole or primary service. None identified solely as a charitable organisation, however two of the case study organisations identified partner charitable Foundations which raise funds for the organisation through private philanthropy and public donations (Schalm [36], Radnor and Lovell [37]).

\section{Organisational performance frameworks and measures}

Table 4 identifies the organisational performance framework and the organisational performance measures for each study. Three different organisational performance frameworks were used - the Balanced Scorecard (BSC) was used in two studies (Schalm [36], Radnor and Lovell [37]), a Primary Health Care Attributes Scale (Laamanen et al. [13]) and The Looking Glass Evaluation Tool (Mueller [3]). Twenty organisational performance measures were used across the four studies and these were themed by the authors into five categories - Quality of Healthcare Service; Finance; Stakeholders (Customers and Clients); People and Culture and Governance and Business Management.

\section{Discussion}

This study completed a systematic search and has demonstrated the limited extent of literature relating to organisational performance of non-acute healthcare charities. There were no published studies identified relating specifically to charities that provide non-acute care in their service scope. No studies were found that evaluate the feasibility, validity or effectiveness of applying an organisational performance measurement framework to improving organisational performance or patient outcomes in this sector. No studies comparatively evaluated measures to identify the most valuable measures in determining performance of such organisations. 


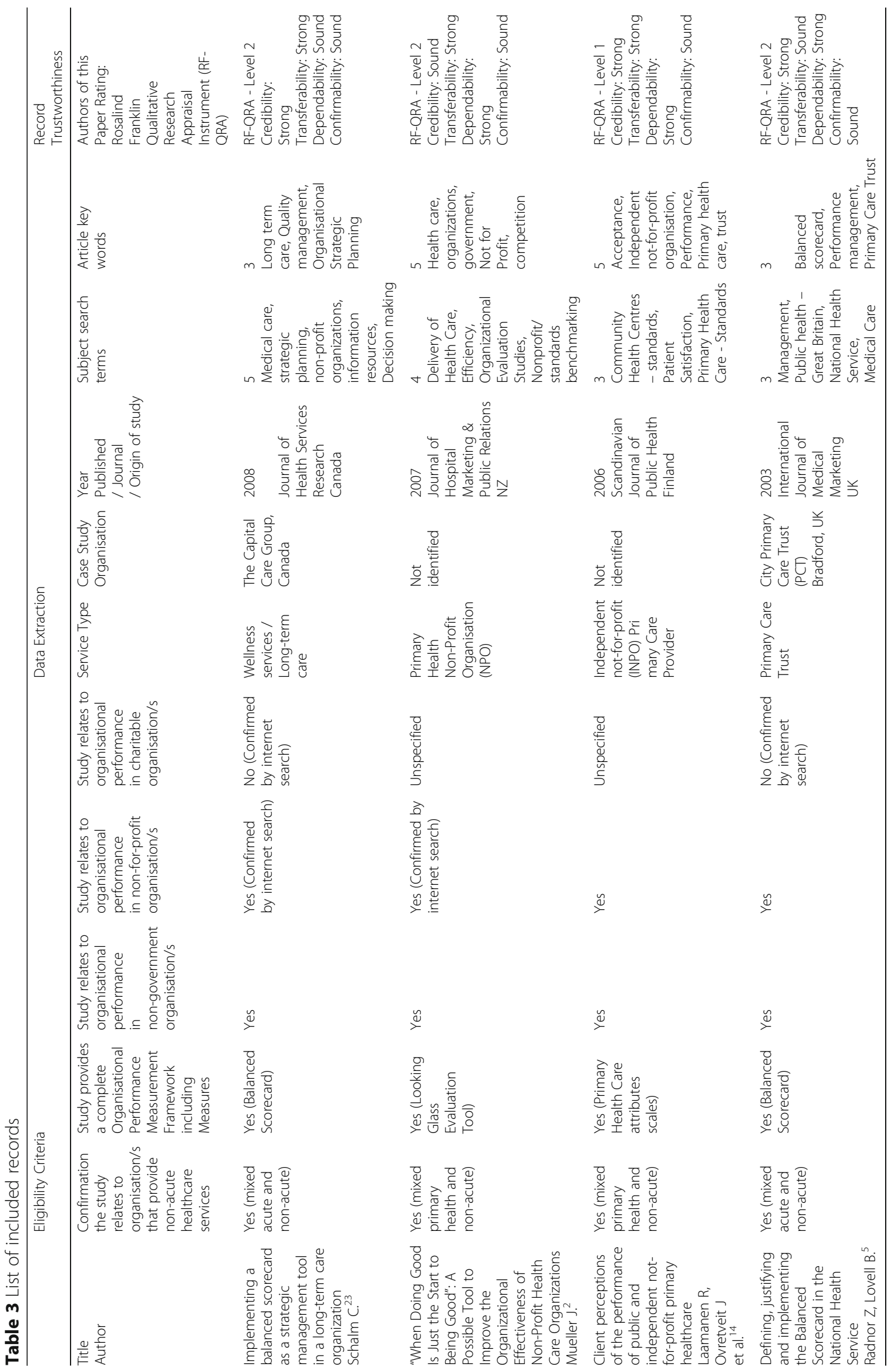


Table 4 Organisational Performance Frameworks and Measures

\begin{tabular}{|c|c|c|c|c|c|c|c|}
\hline \multirow[t]{2}{*}{ Paper } & \multirow[t]{2}{*}{ Framework } & \multirow{2}{*}{$\begin{array}{l}\text { Number of } \\
\text { Measures }\end{array}$} & \multicolumn{5}{|l|}{ Measure } \\
\hline & & & Quality of Service & Finance & $\begin{array}{l}\text { Stakeholders - } \\
\text { Customers \& } \\
\text { Clients }\end{array}$ & $\begin{array}{l}\text { People \& } \\
\text { Culture }\end{array}$ & $\begin{array}{l}\text { Governance \& } \\
\text { Business Management }\end{array}$ \\
\hline $\begin{array}{l}\text { "When Doing Good Is } \\
\text { Just the Start to Being } \\
\text { Good": A Possible } \\
\text { Tool to Improve } \\
\text { the Organizational } \\
\text { Effectiveness of } \\
\text { Non-Profit Health } \\
\text { Care Organizations } \\
\text { Mueller, J. Journal } \\
\text { Of Hospital Marketing } \\
\text { \& Public Relations } \\
\text { 2007; } 17 \text { (2): 45-60. }\end{array}$ & $\begin{array}{l}\text { Looking Glass } \\
\text { Evaluation } \\
\text { Tool }\end{array}$ & 6 & & $\begin{array}{l}\text { Financial and } \\
\text { Asset } \\
\text { Management } \\
\text { Fundraising } \\
\text { Sustainability }\end{array}$ & & & $\begin{array}{l}\text { Governance - } \\
\text { Strategic Management } \\
\text { Management Practices } \\
\text { Risk Management }\end{array}$ \\
\hline $\begin{array}{l}\text { Client perceptions } \\
\text { of the performance } \\
\text { of public and } \\
\text { independent } \\
\text { not-for-profit } \\
\text { primary healthcare } \\
\text { Laamanen, R, } \\
\text { Ovretveit, J et al. } \\
\text { Scandinavian } \\
\text { Journal of Public } \\
\text { Health 2006; } 34 \\
\text { (6): 598-608. }\end{array}$ & $\begin{array}{l}\text { Primary } \\
\text { Health Care } \\
\text { attributes } \\
\text { scales }\end{array}$ & 5 & $\begin{array}{l}\text { Accessibility } \\
\text { Comprehensiveness } \\
\text { Continuity } \\
\text { Accountability } \\
\text { (Quality of Care) }\end{array}$ & & Trust & & \\
\hline $\begin{array}{l}\text { Defining, justifying } \\
\text { and implementing } \\
\text { the Balanced } \\
\text { Scorecard in the } \\
\text { National Health } \\
\text { Service } \\
\text { Radnor, Z, Lovell, B. } \\
\text { International Journal } \\
\text { of Medical Marketing } \\
2003 ; 3 \text { (3): 174-189. }\end{array}$ & $\begin{array}{l}\text { Balanced } \\
\text { Scorecard }\end{array}$ & 4 & & $\begin{array}{l}\text { Cost } \\
\text { Perspective }\end{array}$ & $\begin{array}{l}\text { Client Perspective } \\
\text { (Themed here } \\
\text { because doesn't } \\
\text { specifically call } \\
\text { out quality of } \\
\text { care, instead } \\
\text { looks to utilise } \\
\text { traditional } 4 \text { BSC } \\
\text { perspectives) }\end{array}$ & $\begin{array}{l}\text { Learning \& } \\
\text { Growth }\end{array}$ & Internal Processes \\
\hline \multirow[t]{2}{*}{$\begin{array}{l}\text { Implementing a balanced } \\
\text { scorecard as a strategic } \\
\text { management tool in a } \\
\text { long-term care } \\
\text { organization } \\
\text { Schalm, C. Journal of } \\
\text { Health Services Research } \\
\text { \& Policy 2008; } 1 \text { (13): 8-14. }\end{array}$} & $\begin{array}{l}\text { Balanced } \\
\text { Scorecard }\end{array}$ & 5 & & & $\begin{array}{l}\text { Clients (Themed } \\
\text { here because } \\
\text { does not } \\
\text { specifically call } \\
\text { out quality of care) } \\
\text { Stakeholders } \\
\text { Community } \\
\text { Partnerships }\end{array}$ & $\begin{array}{l}\text { People, } \\
\text { Learning } \\
\text { \& Research }\end{array}$ & Internal Processes \\
\hline & $\begin{array}{l}\text { BSC } \\
2 / 4(50 \%)\end{array}$ & $\begin{array}{l}20 \\
(A V: 5)\end{array}$ & $4(20 \%)$ & $4(20 \%)$ & $5(25 \%)$ & $2(10 \%)$ & $5(25 \%)$ \\
\hline $\begin{array}{l}\text { Number of papers that } \\
\text { refer measures in that } \\
\text { theme }\end{array}$ & & & $1(25 \%)$ & $2(50 \%)$ & $3(75 \%)$ & $2(50 \%)$ & $3(75 \%)$ \\
\hline
\end{tabular}

\section{Value and feasibility}

Considering the extent of published literature supporting organisational performance in the for-profit sector, and the increasing recognition of such business tools in the NGO and NFP sectors, the lack of demonstrable evidence to support its use and development within non-acute healthcare charities is an important finding. The four eligible studies were all published before 2009, originated from different countries and utilised highly varied key words and search terms, which may reinforce the limited extent of awareness or use of organisational performance measurement in the sector.

Richard et al. ([6], p. 719) report that the capability to accurately measure and report organisational performance is "essential to the survival and success of the modern business". Harvey and Snyder suggest "smart non-profits are finding that goal-oriented management, combined with yardsticks to measure progress, may mean the difference between success and failure" ([20], p. 14). It is therefore reasonable to suggest that 
organisational performance measurement for non-acute healthcare charities would likely be of value.

Radnor and Lovell found that the majority of successful organisations within a market-based economy "use PMSs (sic. performance management systems) of varying degrees of sophistication" ([37], p. 175). As the four eligible records identify case studies that demonstrate the design of frameworks and measures, it is reasonable to suggest that similar would be feasible for development for non-acute health charities.

\section{Organisational performance frameworks}

Three organisational performance frameworks were utilised within the study's four records (Table 3). No evidence garnered through this systematic review suggests none of those organisational performance frameworks is more suited to this sector than another, however only the Balanced Scorecard (BSC) featured more than once. The BSC is worth investigating as an organisational performance measurement framework tool for the non-acute health charity sector as it "prevails as the dominant performance measurement system in private industry" ([38], p. 427), is used in "government, and non-profit organisations worldwide" ([22], p. 104), can be applied in healthcare ([39], p. 260) and was widely referenced and utilised in records sourced that did not meet all of the study's inclusion criteria. The other identified frameworks - The Looking Glass Evaluation Tool [3] and Primary Care Health Attributes scale [13] were not widely used.

\section{Organisational performance measures}

The importance of tailored sector-type and individual organisational performance measures as success reference points within conceptual frameworks and the difficulty in developing organisational performance measures for non-profits has been recognised. The study did not source any comparative studies that identify the most valuable measures for the non-acute healthcare providers in NGO, NFP and charity sectors. As such, this study contributes to the body of knowledge by being the first to propose a set of evidence-informed organisational performance measures specifically for non-acute health charities.

There were 20 organisational performance measures identified within the four assessed studies (Table 4), which were themed by the authors into five common categories. These could now be tested as measures for NGO non-acute healthcare providers in the NFP or charity sectors:

- Quality of Service

- Finance

- Stakeholders (Customers and Clients/Patients)

- People and Culture

\section{- Governance and Business Management}

Three of the four studies included measures that related to Governance and Business Management. Two of those used Kaplan and Norton's traditional 'Internal Processes' perspective for BSC ([40], p. 54). Mueller [3] identified governance, strategic management, management practices and risk management as key measures. Table 4 reveals factors that can be considered to broaden the range of the Governance and Business Management measures used in this sector.

The importance of stakeholders including clients or patients, was clearly demonstrated. In terms of health care, the World Health Organisation's European Ministerial Conference Report maps important accountability relationships across seven stakeholder groups within health systems ([21], p. 2) - patients, citizens, clinician, government, profession, provider organisation, purchaser organisation; and acknowledges their different needs. The expectations and needs of each stakeholder group vary and not just in relation to patience outcomes. Subsequently, performance measures, for each group could be considered. Three of the four studies included measures relating to the engagement and satisfaction of stakeholders. In healthcare, Bisbe et al. [28] noted that some organisations have placed client and financial perspectives at the apex of their BSC "thus assigning them equal importance" ([28], p. 923). For non-profits, Gomes and Liddle's study [27] corroborated Kaplan and Norton's [40] suggestion that non-profit organisations should put customers at the top of their strategic maps and three of Zimmerman's (2009) six recommended BSC measurement perspectives for NFPs related to stakeholders ([25], p. 10). The value of stakeholders or customers to charities was demonstrated by Boateng et al. [16] in that two of five recommended organisational performance measures for charities related to client satisfaction and stakeholder involvement and it was noted that "the overall performance of charities is best measured by a set of factors that reflect the multiple and diverse stakeholders associated with charities" ([16], p. 59) and that non-financial measures including stakeholder involvement are important to the performance of charities ([16], p. 59).

Quality of Service as an organisational measure strengthens attention to an organisation's core service. Gurd and Gao reiterated that patients are "the focus of healthcare services" ([17], p. 17) and Bisbe et al. ([28], p. 922) noted that some healthcare organisations have an additional measurement perspective on clinical outcomes. Three of the four studies included performance indicators relating to service satisfaction and one specifically noted the importance of Quality of Care to organisational performance ([13], p. 600).

In terms of financial considerations for organisational performance, the issue appears to be more focused on 
'where', not 'if', finance sits in a healthcare BSC. Bisbe et al. [28] discuss the "increasing resistance within healthcare organisations, especially those in the public health sector, to placing the financial perspective at the apex of the strategy map" ([28], p. 923). Two of the four studied papers included finance measures within their frameworks.

Two of the four studies identified people, learning and growth as important measures. As Kaplan and Norton ([41], p. 257) suggest organisational learning and growth are generated from people not just systems, and subsequently People and Culture was identified as a stand-alone measure outside of Governance and Business Management.

Further investigation of records that had not met all of the eligibility criteria highlighted that some non-profit health organisations seek an organisational performance measure that assesses performance against "achieving the organisation's final objective" ([28], p. 923). Colbran et al. [14] suggested such a measure be titled 'Mission and Purpose' and this may have merit as inclusion as a sixth organisational performance measure for non-acute health charities.

\section{Study limitations}

The authors identified limitations to the study that should be considered when interpreting the results and recommendations. These limitations also reinforce the need for further study. While limited source or empty reviews are defendable, the study's primary limitation is the small number of data sources due to the fact that no studies were found that related solely to organisational performance of non-acute healthcare charities and that only four records met the inclusion criteria. Extending the systematic review criteria beyond peer-review published literature to include grey literature (sourced outside the peer-reviewed literature), or through less restrictive eligibility criteria, may have identified reports of additional eligible records. However, if the latter had been applied, the lack of literature on performance measurement in non-acute healthcare charities sector would have been lost.

\section{Implications for further study}

The present study identifies the need for quality methodological studies of organisational performance measurement frameworks for non-acute healthcare charities. Identifying the reasons for the lack of published evidence relating to organisational performance measurement in this sector could encourage awareness and greater knowledge sharing within the sector. The present study lists frameworks and measures and a comparative evaluation of these frameworks to understand their appropriateness and inform their selection within the sector would be of value.

In terms of effective deployment, further research to understand and validate the five $\mathrm{BSC}$ recommended organisational performance measures, with the additional inclusion of 'Mission and Purpose' is recommended, along with identification and analysis of indicators to support each measure. Research to understand the important factors for organisational performance implementation within non-acute healthcare charities is also recommended. Demonstrating impact and validating the degree of value of the full-scaled deployment of a tailored set of measures utilising an evidence-based framework such as the BSC would further inform the value of organisational performance measurement to organisations in the sector.

Finally, the opportunity to utilise organisational performance measurement to support whole-of-sector development is worth considering. While acknowledging there will always be some differences due to the different strategic orientations of health care organisations, Gurd et al. [17] encouraged health care organisations to work in groups of like organisations to produce scorecards which are both comparable but meet their own strategic needs. The aggregation of sector-specific knowledge can complement health related accreditation frameworks and enable benchmarking by providing "national or state-based pictures of performance" Sibthorpe and Gardner ([42], p. 102).

\section{Conclusions}

The nonprofit sector continues to grow globally and so too does concern regarding the effectiveness and accountability of non-government organisations, not-for-profits and charities. Organisational performance measurement is a recognised business management tool and it has been suggested as being essential for success and survival. A relationship between performance measurement and organisational effectiveness in nonprofit organisations has been identified yet uptake in some nonprofit sectors has been slow. In healthcare, non-acute health charities form part of the broader global industry and play a role in non-hospital care however there is a literature gap in organisational performance for this sector.

This study found there is a paucity of methodological studies of organisational performance measurement relating to non-acute healthcare charities and concluded that (1) demonstration of organisational performance is relevant to non-acute health charities; (2) organisational performance measurement is feasible in this sector; (3) an evidence-based organisational performance measurement framework or tool specifically for the sector has not yet been developed, nor has an existing 
organisational performance measurement framework yet to be adapted for the sector, although the Balanced Scorecard is likely to be an effective option and (4) five leading measures - Quality of Service; Finance; Stakeholders (Customers and Clients); People and Culture and Governance and Business Management; could be used to determine organisational performance in these sectors.

Further study to understand and validate the five recommended organisational performance measures complemented by a sixth measure - Mission and Purpose, which was identified in the broader literature, would be valuable. Further exploration to understand why there is such limited published organisational performance evidence for the sector could be useful, as would consideration as to which existing organisational performance measurement frameworks might be most successfully adapted for the sector. Case studies of organisational measurement strategies of successful non-acute healthcare charities and research into important factors for organisational performance implementation in the sector may also contribute to greater uptake and knowledge dissemination.

\section{Abbreviations}

BSC: Balanced Scorecard; INPO: Independent not-for-profit organization (INPO); NFP: Not-for-profit; NGO: Non-government organisation; PCT: Primary Care Trust; PHO: Primary Health Organization; PRISMA: Preferred Reporting Items for Systematic Reviews and Meta-Analyses; RF-QRA: The Rosalind Franklin Qualitative Research Appraisal Instrument

\section{Acknowledgements}

Not applicable.

\section{Funding}

No funding was received for this study. The research reported in this paper is the sole responsibility of the authors and reflects the independent work of the authors.

\section{Availability of data and materials}

Data sharing is not applicable to this article as no datasets were generated or analysed during the current study.

\section{Authors' contributions}

The study was designed by RC in collaboration with RR, KS and JT. RC led data collection and analysis. RR and KS supported data analysis. RC drafted manuscript. All authors critically reviewed the manuscript, provided significant editing of the article and approved the final manuscript.

\section{Ethics approval and consent to participate}

Not applicable.

\section{Consent for publication}

Not applicable.

\section{Competing interests}

The authors declare that they have no competing interests.

\section{Publisher's Note}

Springer Nature remains neutral with regard to jurisdictional claims in published maps and institutional affiliations.

\section{Author details}

${ }^{1}$ New South Wales (NSW) Rural Doctors Network, Hamilton, NSW, Australia. ${ }^{2}$ School of Health and Social Development, Deakin University, Melbourne, VIC, Australia. ${ }^{3}$ School of Psychology, Deakin University, Melbourne, VIC, Australia.

Received: 26 October 2018 Accepted: 14 February 2019

Published online: 22 February 2019

\section{References}

1. Fonseca S, Baptista A. Market orientation, organisational learning, innovation and performance: keys to the sustainability of non-profits. Eur Scient J. 2013; http://hdl.handle.net/10400.19/4189.

2. Dickerson C, Grills N, Henwood N, Jeffreys S, Lankester T. The World Health Organization Engaging with Civil Society Networks to Promote Primary Health Care: A Case Study. Global Health Governance. 2012;Vl:1 Retrieved from http://blogs.shu.edu/ghg/files/2012/12/GHGJ-VOLUME-VI-ISSUE-1-FALL2012-The-World-Health-Organization-Engaging-with-Civil-Society-Networksto-Promote-Primary-Health-Care-A-Case-Study.pdf.

3. Mueller J. When doing good is just the start to being good: a possible tool to improve the organizational effectiveness of non-profit health care organizations. J Hosp Mark Public Relations. 2007;17(2):45-60.

4. Kaplan R. Strategic performance and management in nonprofit organisations. Nonprofit Manag Leadership. 2001;11(3):353-70.

5. Lecy J, Schmitz H, Swedlund H. Non-governmental and not-for-profit organizational effectivess: a structured literature review. Voluntas. 2010;23:434-57.

6. Richard P, Devinney T, Yip S, Johnson G. Measuring organizational performance: towards methodological best practice. J Manag. 2009;35(3): 718-804.

7. Kirk G, Beth Nolan S. Nonprofit mission statement focus and financial performance. Nonprofit Manag Leadership. 2010;20(4):473-90.

8. Moullin M. Performance measurement definitions; linking performance measurement and organisational excellence. Int J Health Care Qual Ass. 2007;20(3):181-3.

9. Weir E, d'Entremont N, Stalker S, Kurji K. Robinson, applying the balanced scorecard to local public health performance measurement: deliberations and decisions. BMC Public Health. 2009;9:127. https://doi.org/10.1186/14712458-9-127.

10. Pieper $\mathrm{SH}$. Reading the right signals: how to strategically manage with scorecards. Healthc Exec. 2005;20(3):9-14.

11. Zelman WN, Pink GH, Matthias CB. Use of the balanced scorecard in health care. J Health Care Finance. 2003;29(4):1-16.

12. Wadongo B, Abdel-Kader M. Contingency theory, performance management and organisational effectiveness in the third sector: a theoretical framework. Int J Product Perform Manag. 2014;63(6):680-703.

13. Laamanen R, Ovretveit J, Sundell J. Client perceptions of the performance of public and independent not-for-profit primary healthcare. Scand J Public Health. 2006:34(6):598-608.

14. Colbran R, Ramsden R, Stagnitti K, Adams S. Measures to assess the performance of an Australian non-government charitable non-acute health service: a Delphi survey of Organisational stakeholders. Health Serv Manag Res. 2017;31(1):11-20. https://doi.org/10.1177/0951484817725681.

15. Foot C, Sonola L, Bennett L, Fitzsimons B, Raleigh VS, Gregory S. Managing quality in community health care services. London: The Kings Fund; 2014.

16. Boateng A, Akamavi R, Ndoro G. Measuring performance of non-profit organisations: evidence from large charities. Bus Ethics Eur Rev. 2016;25(1): 59-74.

17. Gurd B, Gao T. Lives in the balance: an analysis of the balanced scorecard (BSC) in healthcare organizations. Int J Product Perform Manag. 2008;57(1):6-21.

18. Neely A, Bourne M. Why measurement initaitives fail. Meas Bus Excell. 2000; 4(4):3-7. https://doi.org/10.1108/13683040010362283.

19. Clarke W. Introducing strategic thinking to nonprofit organisation to develop alternative income streams. J Pract Consult. 2012:4(1):32-42.

20. Harvey P, Snyder D. Charities need a bottom line too. Harv Bus Rev. 1987;65: 14-9.

21. Smith P, Mossialos E, and Papanicolas, I. Performance measurement for health system improvement: experiences, challenges and prospects. WHO European Ministerial Conference on Health Systems, Tallin, Estonia June 2008. http://www.who.int/management/district/performance/ PerformanceMeasurementHealthSystem/mprovement2.pdf (Accessed 10 Oct 2018). 
22. Grigoroudis E, Orfanoudaki E, Zopounidis C. Strategic performance measurement in a healthcare organisation: a multiple criteria approach based on balanced scorecard. Omega. 2012;40(1):104-19.

23. Hafeez K, Malak N, Abdelmeguid H. A framework for TQM to achieve business excellence. Total Qual Manag Bus Excell. 2006;17(9):1213-29. https://doi.org/10.1080/14783360600750485.

24. Purcell ME, Hawtin M. Piloting external peer review as a model for performance improvement in third-sector organizations. Nonprofit Manag Leadership. 2010;20(3):357-74. https://doi.org/10.1002/nml.258.

25. Zimmerman J. Using a balanced scorecard in a nonprofit organization. Nonprofit World. 2009;27(3):10-2

26. Martello M, Watson J, Fischer M, Implementing A. Balanced scorecard in a not-for-profit organization. J Bus Econ Res. 2008;6(9):67-80

27. Gomes R, Liddle J. The balanced scorecard as a performance management tool for third sector organizations: the case of the Arthur Bernardes Foundation, Brazil. BAR. 2009;6(4):354-66.

28. Bisbe J, Barrubes J. The balanced scorecard as a management tool for assessing and monitoring strategy implementation in health care organizations. Revista Espanola de Cardiologia. 2012;65(10):919-27.

29. Haddaway N. The importance of meta-analysis and systematic reiews: How research legacy can be maximised through adequate reporting. Blog post retrieved from http://blogs.lse.ac.uk/impactofsocialsciences/2015/01/26/theimportance-of-meta-analysis-and-systematic-review/. (Accessed 10 Oct 2018).

30. Moher D, Liberati A, Tetzlaff J, Altman D. Preferred Reporting Items for Systematic Reviews and Meta-Analyses: The PRISMA Statement. PLoS Medicine (OPEN ACCESS). 2009;6(7):e1000097. https://doi.org/10.1371/ journal.pmed1000097.

31. Equator-network.org. The EQUATOR Network, Enhancing the QUAlity and Transparency of Health Research. Available at: http://equator-network.org/ (Accessed 19 Apr 2016).

32. Ryan G, Bernard R. Techniques to identify themes. Field Methods. 2003; 15(1):85-109.

33. Yaffe J, Montgomery P, Hopewell S, Shepard L. Empty reviews: a description and consideration of Cochrane systematic reviews with no included studies. PLoS One. 2012;12(5):e36626. https://doi.org/10.1371/journal.pone.0036626.

34. Lang A, Edwards N, Fleiszer A. Empty systematic reviews: hidden perils and lessons learned. J Clin Epidemiol. 2007;60:595-7.

35. Henderson R, Rheault W. Appraising and incorporating qualitative research in evidence-based practice. J Phys Ther Edu. 2004;18(3):35-40.

36. Schalm C. Implementing a balanced scorecard as a strategic management tool in a long-term care organization. J Health Serv Res Policy. 2008;1(13):814.

37. Radnor Z, Lovell B. Defining, justifying and implementing the balanced scorecard in the National Health Service. Int J Med Mark. 2003;3(3):174-89.

38. Bhagyashree P, Rossiter M, Pantano V. Performance measurement systems: successes, failures and future - a review. Meas Bus Excell. 2006;10(3):4-14.

39. Groene O, Brandt E, Schmidt W, Moeller J. The balanced scorecard of acute settings: development process, definition of 20 strategic objectives and implementation. Int J Qual Health Care. 2009;21 (4):259-71.

40. Kaplan R, Norton D. Transforming the balanced scorecard from performance measurement to strategic management: part I. Account Horiz. 2001;15(1): 87-104.

41. Kaplan R, Norton D. Linking the balanced scorecard to strategy. Calif Manag Rev. 1996;39(1):53-79.

42. Sibthorpe B, Gardner K. A conceptual framework for performance assessment in primary healthcare. Aus J Primary Health. 2007;13(2):96-103.

Ready to submit your research? Choose BMC and benefit from:

- fast, convenient online submission

- thorough peer review by experienced researchers in your field

- rapid publication on acceptance

- support for research data, including large and complex data types

- gold Open Access which fosters wider collaboration and increased citations

- maximum visibility for your research: over $100 \mathrm{M}$ website views per year

At BMC, research is always in progress.

Learn more biomedcentral.com/submissions 